\title{
Intra-Individual Variability in Self-Reported Use of Non-Steroidal Anti-Inflammatory and Analgesic Medicines Depending on Mode of Data Collection - Observations from the Population Study of Women in Gothenburg, Sweden
}

\author{
Helle Håkonsen (1D) \\ Dominique Hange (iD ${ }^{1,2}$ \\ Tove Hedenrud' \\ 'School of Public Health and Community \\ Medicine, Institute of Medicine, \\ University of Gothenburg, Gothenburg, \\ SE 405 30, Sweden; ${ }^{2}$ Region Västra \\ Götaland, Education, Research and \\ Development Primary Health Care, \\ Skövde, 54I 80, Sweden
}

\begin{abstract}
Background: Self-report by questionnaire is one of the main methods to collect data on drug utilization. There are several modes of data collection by questionnaire, differing in the way of delivering the questionnaire to respondents and in the administration of the questions, both influencing the recall and participation rates. The aim of this study was to compare different modes of data collection for self-reported use of non-steroidal anti-inflammatory (NSAIDs) and analgesic medicines.
\end{abstract}

Methods: Data on 573 women (38 or 50 years) were retrieved from the Population Study of Women in Gothenburg. Data on medicine use were collected using two different modes: (1) a self-administered questionnaire with closed-ended medicine-specific questions; and (2) an interviewer-administered questionnaire with open-ended questions. Cohen's kappa statistics were applied to assess the agreement of the two modes.

Results: The proportion of participants that reported use of NSAIDs and analgesics was higher with the self-administered questionnaire compared with the interviewer-administered questionnaire $(69.3 \%$ vs $58.5 \%, p<0.001)$. The overall agreement between the two modes of data collection was fair $(\mathrm{K}=0.27)$, ranging from none for antimigraine preparations to fair $(\mathrm{K}=0.36)$ for NSAIDs. A higher proportion of the participants aged 38 years reported use of NSAIDs and analgesics compared with the 50-year olds. In the regression model using data from the selfadministered questionnaire, all four categories of bodily pain were significant predictors for use of NSAIDs and analgesics. The most severe reported bodily pain was the only significant predictor in the model using data from the interviewer-administered questionnaire.

Conclusion: This study showed that use of a self-administered questionnaire with closed-ended medicine-specific questions identified more users of NSAIDs and analgesic medicines compared with an interviewer-administered questionnaire with open-ended questions. Reported use according to the self-administered questionnaire was also more strongly associated with experienced pain.

Keywords: analgesics, medicine use, NSAIDs, population study, questionnaire, self-report, women

\section{Introduction}

School of Public Health and Community Medicine, Institute of Medicine, University of Gothenburg, P.O. Box 453,

Gothenburg, SE 405 30, Sweden

Email helle.hakonsen@gu.se
Studies of drug utilization can provide important information about the intended and unintended effects of medicines. Drug utilization data, which can be collected from biological samples, prescribing or pharmacy records, and questionnaires, form 
the basis for research, therapy guidelines, and clinical decisions. However, these sources can be unreliable in terms of whether and to what extent patients actually were exposed to the medicine in question. ${ }^{1}$ Individual differences in drug metabolism, ${ }^{2}$ non-adherence to prescribed or acquired medicines, ${ }^{3}$ and inaccurate selfreporting ${ }^{4}$ are all factors that may contribute to uncertain data and misleading information.

Prescription drug registers are used quite extensively for pharmaco-epidemiological research. The Swedish register contains a complete collection of pharmacy records and includes personal identification numbers that enable linkage to other registers. ${ }^{5}$ However, the use of registers has its clear limitations. First of all, data on the acquisition of medicines in the pharmacy tend to overestimate actual consumption, ${ }^{6}$ especially in countries with broad reimbursement systems where most of the medicine expenditures are not carried by the users themselves. Another limitation is the lack of data on acquisition of over-the-counter (OTC) medicines.

Regarding OTC medicines, self-report by questionnaire is the main method to collect data on their utilization. There are several modes of data collection by questionnaire, differing in the way of delivering the questionnaire to respondents and in the administration of the questions, both influencing the recall and participation rates. ${ }^{7}$ Questionnaires can be administered by the respondent or by an interviewer (on site or by telephone), whereby the latter is preferred in order to maximize completeness. ${ }^{8}$ Interviewer-administered surveys conducted in respondents' homes, where the medicine packages are accessible for review, are considered a particularly reliable method for the assessment of current medicine use. ${ }^{9}$ This mode of data collection reduces the risk of recall bias (possible underreporting) and misclassification and is useful for discovering acquired but unused medicines. It is, however, resource-demanding and time-consuming; hence, most self-reports are conducted at other locations than respondents' homes. Thus, utilization studies of OTC medicines are often completely reliant on respondents' recall, which is known to decline significantly about two-three weeks after intake of a medicine. ${ }^{10}$ While recall may be satisfactorily accurate for prescription medicines used for chronic diseases, more sporadic use of OTC medicines is often less accurately reported, ${ }^{9-11}$ especially during illness that is more acute and during pregnancy. ${ }^{12}$ There are also problems regarding what to report, increasing the risk of underreporting as well as misclassification. The understanding of which products should be classified as medicines is far from obvious when regarding OTC medicines, which may be placed on the shelves next to other types of products and are widely sold by non-pharmacy retailers in many countries.

Methodological studies addressing the effect of questionnaire design on the recall of medicine use show that closed-ended, medicine-specific questions and questions regarding indication for use increase the prevalence estimates for use compared with open-ended questions. ${ }^{13-15}$ Furthermore, the order in which the responses are presented has been shown to influence recall, ${ }^{16}$ even when closed-ended questions asking for specific medicines are used. ${ }^{17}$ Lunet et al found that for self-administered questionnaires, respondents were more likely to begin processing the first response option presented (primacy effects), while in face-to-face or telephone interviews, respondents began with the final option offered (recency effects). ${ }^{17}$ Factors that have been associated with sensitivity of recall are respondents' age, ${ }^{11,13}$ educational level, ${ }^{11-13}$ selfreported health status, ${ }^{13}$ type of medicine, ${ }^{13}$ and duration of use. $^{13}$

In several of the above mentioned studies, ${ }^{11,13}$ drug utilization data from questionnaires were compared with pharmacy records. Despite the risk of overestimation, the latter is often used as control, and the studies suggest that self-reported drug exposure may be considerably underreported. Since comparison with pharmacy records is not possible in studies that include OTC medicines, comparing self-reported data collected by different means is the most reliable approach, but such research is scarce. Ademi et al used self-reported data from a prospective, populationbased cohort study in Finland to compare three different ways of asking respondents about prescribed and OTC analgesic use. ${ }^{18}$ Their study demonstrated considerable variability in the results for different measures, ie, a higher prevalence of reported use for an open-ended question ("name any analgesic that you have been using during the previous week") when compared with questions about frequency of use and when asking about use for a stated pain condition. In none of the questions were specific medicine names mentioned for the respondents. ${ }^{18}$ It is obvious that more research is needed in the strive for a golden standard for high quality and valid measures of OTC medication use.

In the Population Study of Women in Gothenburg, data on drug utilization were collected by two different modes of self-report, which makes it possible to compare the 
different methods and investigate possible associations with data on experienced pain. The aim of this populationbased study was to compare different modes of data collection, ie, question design and administration, in relation to reported use of non-steroidal anti-inflammatory (NSAIDs) and analgesic medicines.

\section{Methods}

\section{Setting}

The Population Study of Women in Gothenburg was started in $1968 .^{19}$ The main purpose of the study is to examine determinants that have importance for the development of physical and mental disease among middleaged women. The collected data provide the opportunity to study both longitudinal trends (change in individuals over time) and secular trends (changes in the population over time). ${ }^{20}$ Since its start, approximately 3000 women aged 38, 46, 50, 54, 60 and 75 years have participated in the study. Six repeated data collections have been conducted on the original and new cohorts of women aged 38 and 50 years old. Each round of data collection has contained questionnaires on risk factors, lifestyle, symptoms and medicine use, and physical examinations at a study clinic at the University of Gothenburg.

During the three first examinations (1968-69, 197475, 1980-81), a self-administered questionnaire was used to collect information on the use of medicines. At the later examinations (1992-93, 2004-05), a different questionnaire was used, and the questions about medicine use were posed by a research assistant (a nurse) at the study clinic. In the last data collection in 2016-17, both modes of data collection on medicine use were applied, providing a possibility to compare the information about medicines obtained from two different modes of data collection.
The response rates for the studies have decreased since the first cohort was recruited, from $90 \%$ in 1968 to $69 \%$ in 2016-17.

\section{Methods}

Data collection for this study was conducted from October 2016 to June 2017. The first questionnaire was filled in by the respondents at home before their first appointment at the study clinic. Most respondents visited the clinic 1-3 weeks after they received the survey in the mail. At the clinic, the questionnaire was checked for completeness and, if necessary, completed with the assistance of the research assistant. The questionnaire was comprehensive, including topics such as living conditions during childhood, working life, sick leave, previous and current illnesses, pain conditions, medicine use, hospitalization and surgical interventions as well as eating and sleeping habits. Sixteen items concerned current medicine use, four of which regarding NSAIDs and analgesics. These items were phrased as closed-ended questions; the wording after translation into English is presented in Table 1. Questions regarding bodily pain during the past 4 weeks were taken from the Short Form (36) Health Survey and scored according to the instructions. ${ }^{21}$

The second data collection was conducted at the study clinic. The questionnaire was brief, consisting of openended questions regarding medicine use (see Table 1 for the wording after translation into English). Four research assistants were involved in collecting data. A total number of medicines in current use per respondent was calculated based on the collected data from this questionnaire.

\section{Analyses}

All medicines were coded according to the ATC (Anatomical Therapeutic Chemical) classification system. Reported use concerned the following ATC groups: M01A

Table I Wording of the Questions Regarding Medicine Use in the Two Questionnaires

\begin{tabular}{|c|c|c|}
\hline & $\begin{array}{l}\text { Self-Administered } \\
\text { Questionnaire }\end{array}$ & $\begin{array}{c}\text { Interviewer-Administered } \\
\text { Questionnaire }\end{array}$ \\
\hline Medicine use & $\begin{array}{l}\text { Are you using (daily, weekly or } \\
\text { monthly) } \\
\ldots \text { tablets with salicylates*? } \\
\ldots \text { tablets with NSAIDs**? } \\
\ldots \text { other painkillers***? } \\
\ldots \text { antimigraine tablets? }\end{array}$ & $\begin{array}{l}\text { Considering any medicine you have been } \\
\text { prescribed by a doctor or purchased without } \\
\text { a prescription in a pharmacy, what are you } \\
\text { using? }\end{array}$ \\
\hline
\end{tabular}

Notes: *Examples of products containing acetylsalicylic acid were given. **Examples of products containing naproxen, ibuprofen and diclofenac were given. ***Examples of products containing paracetamol and morphine were given. 
(non-steroid anti-inflammatory and antirheumatic drugs (NSAIDs)) and N02 (analgesics).

Pearson's chi-square tests were used to check for differences in reported prevalence between the two modes of data collection before Cohen's kappa statistics were applied to assess the agreement between the two modes. In this study, $\mathrm{K}$ values $>0.80$ were interpreted as very good, $0.61-0.80$ as good, $0.41-0.60$ as moderate, 0.210.40 as fair and $\leq 0.20$ as minimal agreement.

Pearson's chi-square tests and one-way ANOVAs were used for analyzing possible differences between the two age groups ( $5 \%$ level of significance).

Logistic regression was performed to examine possible associations between age and reported bodily pain during the past 4 weeks and reported use of NSAIDs and analgesics for the two modes of data collection. The scores on bodily pain, which ranged from 0 (the most severe pain) to 100 (no bodily pain), were divided in four categories (025, 26-50, 51-75 and 76-100). Age 38 years and the highest score of bodily pain (76-100) were chosen as reference categories in the analyses. Hosmer-Lemeshow tests were used for testing goodness of model fit. The results are presented as odds ratios (ORs) with $95 \%$ confidence intervals (CIs).
Statistical analyses were performed using IBM SPSS Statistics for Windows, Version 25.0.

\section{Ethical Considerations}

The prospective Population Study of Women in Gothenburg was approved by the ethics committee of the University of Gothenburg and the Regional Ethical Review Board in Gothenburg from 1968 onwards including all later follow-ups (latest DNr 258-16, 20160411). Informed written consent was obtained from all participants. The study was conducted in accordance with the Declaration of Helsinki.

\section{Results}

In all, 573 women, 38 or 50 years of age, participated in the 2016-17 data collection. Table 2 shows the participants' education and experience of bodily pain during the past 4 weeks in relation to age. The mean score of the domain bodily pain was 74.6 (sd: 23.2). There was no significant difference in mean reported bodily pain (76.6 vs 72.9, $p=0.052$ ) between the age groups. A higher proportion of participants aged 38 years, compared with the 50-year olds, reported headache during the past three months $(71.9 \%$ vs $61.8 \%, p=0.011)$, while the prevalence

Table 2 Distribution of the Study Population's Age in Relation to Education, General Health, Bodily Pain During the Past 4 Weeks, and Reported Pain Conditions in Previous 3 Months $(n=573)$

\begin{tabular}{|c|c|c|c|}
\hline & \multicolumn{2}{|c|}{ Age } & \multirow[b]{2}{*}{$p$-value* } \\
\hline & 38 Years $(n=263)$ & 50 Years $(n=310)$ & \\
\hline \multicolumn{4}{|l|}{ Educational level } \\
\hline High school examination or less & $68(26.5 \%)$ & $122(39.7 \%)$ & 0.001 \\
\hline University studies & 189 (73.5\%) & $185(60.3 \%)$ & \\
\hline \multicolumn{4}{|l|}{ Bodily pain during the past 4 weeks** } \\
\hline None & $73(27.9 \%)$ & $74(24.1 \%)$ & 0.279 \\
\hline Very mild to moderate & I 78 (67.9\%) & $212(69.1 \%)$ & \\
\hline Severe or very severe & II (4.2\%) & $21(6.8 \%)$ & \\
\hline \multicolumn{4}{|c|}{$\begin{array}{l}\text { Pain that interfered with normal work during the } \\
\text { past } 4 \text { weeks** }\end{array}$} \\
\hline Not at all & 146 (55.7\%) & $160(52.1 \%)$ & 0.340 \\
\hline A little bit to moderately & I0I (38.5\%) & $120(39.1 \%)$ & \\
\hline Quite a bit to extremely & $15(15.7 \%)$ & $27(8.8 \%)$ & \\
\hline \multicolumn{4}{|c|}{ Type of pain during the past 3 months*** } \\
\hline Headache (incl. migraine) & I87 (7I.9\%) & $189(61.8 \%)$ & 0.011 \\
\hline Joint pain & $50(19.3 \%)$ & $113(36.9 \%)$ & $<0.001$ \\
\hline Back pain & $120(46.2 \%)$ & $130(42.3 \%)$ & 0.363 \\
\hline Pain in legs or knees & $50(19.2 \%)$ & $93(30.3 \%)$ & 0.002 \\
\hline
\end{tabular}

Notes: *Pearson's chi-square. **From the domain "Pain" in the Short Form (36) Health Survey, self-administered questionnaire filled in at home before the first clinic appointment. ***From the interviewer-administered questionnaire with closed-ended questions. Bold text: Significance at a $5 \%$ level. 
Table 3 NSAIDs and Analgesics in Current Use According to Data from Self-Administered Vs Interviewer-Administered Questionnaires $(n=573)$

\begin{tabular}{|c|c|c|c|c|}
\hline \multirow{3}{*}{ Type of medicine (ATC code) } & \multicolumn{2}{|c|}{$\begin{array}{l}\text { Use of Medicines as Reported by Different Modes of Data } \\
\text { Collection }\end{array}$} & \multirow[b]{3}{*}{ Cohen's K } & \multirow[b]{3}{*}{$p$-value } \\
\hline & $\begin{array}{c}\text { Self-administered } \\
\text { questionnaire (closed-ended } \\
\text { questions) }\end{array}$ & $\begin{array}{l}\text { Interviewer-administered } \\
\text { questionnaire (open-ended } \\
\text { questions) }\end{array}$ & & \\
\hline & n (\%) & n (\%) & & \\
\hline NSAIDs and analgesics (MOIA, N02) & $393(69.3 \%)$ & $335(58.5 \%)$ & 0.27 & $<0.001$ \\
\hline NSAIDs (MOIA) & $296(52.4 \%)$ & $191(33.3 \%)$ & 0.36 & $<0.001$ \\
\hline Analgesics (N02) & $319(56.3 \%)$ & $234(40.8 \%)$ & 0.24 & $<0.001$ \\
\hline Opioids (N02A)* & - & $13(2.3 \%)$ & & \\
\hline Other (N02B)* & - & $219(38.2 \%)$ & & \\
\hline Salicylates (N02BA) & $90(16.0 \%)$ & $25(4.4 \%)$ & 0.18 & $<0.001$ \\
\hline Paracetamol (N02BE)* & - & $203(35.4 \%)$ & & \\
\hline Antimigraine preparations (N02C) & $42(7.4 \%)$ & $12(2.1 \%)$ & 0.00 & 0.835 \\
\hline
\end{tabular}

Notes: *Reported as "other analgesics" in the self-administered questionnaire; separate values not available. Bold text: Significance at a $5 \%$ level.

of joint pain and pain in legs or knees was higher among those aged 50 years than those aged $38(36.9 \%$ vs $19.3 \%$, $p<0.001,30.3 \%$ vs $19.2 \%, p=0.002$, respectively). The reported total number of medicines in current use ranged from zero to eight with a mean of 2.1 (sd: 1.8). The mean was 1.9 (sd: 1.5) for the 38-year olds and 2.3 (sd: 1.9) for the 50-year olds ( $p<0.001$; data not shown).

The proportion of participants that reported use of NSAIDs and analgesics was higher when derived from the self-administered questionnaire compared with the interviewer-administered questionnaire $(69.3 \%$ vs $58.5 \%$, $p<0.001)$. As shown in Table 3 , the overall agreement between the two modes of data collection was fair. The highest level of agreement was for reported use of NSAIDs $(\mathrm{K}=0.36)$. For antimigraine preparations, the agreement was no better than chance $(K=0)$.

A higher proportion of the participants aged 38 years reported use of NSAIDs and analgesics compared with the 50-year olds (Table 4). In the regression model using data from the self-administered questionnaire, all three categories of bodily pain during the past 4 weeks were significant predictors for use of NSAIDs and analgesics. The most severe reported bodily pain was the only scoring category predicting the use of NSAIDs and analgesics in the model using data from the interviewer-administered questionnaire.

\section{Discussion}

This study identified significant intra-individual variability in self-reported use of NSAIDs and analgesics depending on mode of data collection. The use of a self-administered questionnaire with closed-ended medicine-specific questions gave higher reported prevalence rates of NSAID and analgesic use compared with an interviewer-administered questionnaire with open-ended questions. Reported use according to the self-administered questionnaire was also more strongly associated with experienced pain. The participants had the possibility to fill in the self-administered questionnaire at home, whereas the intervieweradministered questionnaire took place at the clinic where a nurse asked the questions orally. Several factors probably contributed to the difference in reported use. Firstly, the presence of an interviewer may have introduced a social desirability bias, in the sense that participants may have underreported the use of medicines, a phenomenon that is particularly prevalent regarding use of medicines that are described negatively in media (in this case, eg, paracetamol and opioids). Secondly, the participants did not have their medicines available on site, and this combined with being in a study situation with associated stress might have impaired their recall. Another potential source of bias related to interviewer-administered questionnaires is that questions may have been asked in slightly different ways, with some interviewers being more helpful than others. Furthermore, the participants were asked to report prescription drugs at the same time, which may have taken the focus away from the OTC medicines. Since some OTC analgesics can be bought from non-pharmacy retailers, the phrasing of the question in the interviewer-administered 
Table 4 Adjusted Odds Ratios (ORs) for the Reported Use of NSAIDs and Analgesics by Different Modes of Data Collection in Relation to Age and Experience of Pain During the Past 4 Weeks $(n=573)$

\begin{tabular}{|c|c|c|c|c|c|c|c|c|c|}
\hline & & \multicolumn{4}{|c|}{$\begin{array}{l}\text { Self-Administered } \\
\text { Questionnaire* }\end{array}$} & \multicolumn{4}{|c|}{$\begin{array}{c}\text { Interviewer-Administered } \\
\text { Questionnaire** }\end{array}$} \\
\hline & & $\mathbf{n}$ & $\%$ & OR & $95 \% \mathrm{Cl}$ & $\mathbf{n}$ & $\%$ & OR & $95 \% \mathrm{Cl}$ \\
\hline \multirow[t]{2}{*}{ Age } & 38 years (Ref) & 191 & 73.5 & 1.0 & & 170 & 64.6 & 1.0 & \\
\hline & 50 years & 202 & 65.8 & 0.6 & $0.44-0.89$ & 165 & 53.2 & 0.6 & $0.42-0.83$ \\
\hline \multirow[t]{4}{*}{ Score on bodily pain (past 4 weeks) ${ }^{* * *}$} & $76-100$ (Ref) & 193 & 59.6 & 1.0 & & 180 & 55.2 & 1.0 & \\
\hline & $5 \mathrm{I}-75$ & 115 & 77.2 & 2.5 & $1.66-3.75$ & 90 & 60.4 & 1.3 & $0.87-1.92$ \\
\hline & $26-50$ & 60 & 90.9 & 4.0 & $2.15-7.26$ & 43 & 64.2 & 1.5 & $0.87-2.63$ \\
\hline & $0-25$ & 25 & 92.6 & 7.6 & $2.56-22.63$ & 21 & 77.8 & 3.1 & $1.22-8.02$ \\
\hline
\end{tabular}

Notes: *Hosmer-Lemeshow test of model fit: Chi-square: $0.75(p=0.945)$. **Hosmer-Lemeshow test of model fit: Chi-square: 0.86 ( $p=0.930)$.***Domain from the Short Form (36) Health Survey, self-administered questionnaire filled in at home before the first clinic appointment. Bold text: Significance at a $5 \%$ level.

questionnaire (ie, purchases in a pharmacy) might have led to underreporting. Although pharmacies are the preferred retailer for OTC medicines among Swedish adults, especially women, sales partly take place in grocery stores and similar localities. $^{22,23}$

In this study, the effect of using a self-administered vs interviewer-administered questionnaire cannot be separated from the effect of asking open-ended vs closedended questions. That closed-ended questions increase the reported prevalence rates of medicine use has been confirmed in several studies. ${ }^{13-15}$ For instance, Klungel et al showed that the sensitivity of medicine-specific questions was almost twice as high when compared with openended questions for recall of prescription medicine use. ${ }^{13}$ Furthermore, as previously mentioned, participants may not know what to count as medicines when this involves those sold without prescription. Hence, providing examples may contribute to more accurate reporting. A Swedish study showed that consumers varied in their ability to identify the active substances in commonly used OTC analgesics. When confronted with the names of four active ingredients and a short list of brand names, only one-third were able to match at least three active substances to the correct brand. ${ }^{24}$ This is in line with the results of West et al, which showed that only $30 \%$ of NSAID-users were able to recall the generic or brand name of the medicine. ${ }^{11}$

The participants in this cohort were middle-aged women (38 or 50 years of age) whose average score on general health (SF36 domain) was higher than that reported in a previous population-based study from Gothenburg, ${ }^{25,26}$ indicating a rather healthy study population. Three-quarters reported having experienced bodily pain during the past 4 weeks, ranging from very mild to very severe, and the mean score on bodily pain was 74.6, which implies less pain when compared with the results of the previous study (mean: 69.5). ${ }^{25}$ However, the mean age in the previous study was higher (62.8 years) and $23 \%$ were men.

There was a higher prevalence of reported NSAID and analgesic use among younger women (38 years) compared with older women (50 years), which cannot be explained by more bodily pain during the past 4 weeks, according to Table 2. However, a part of the explanation may be menstrual pain, and that a higher proportion of the 38 -year olds reported having headaches. Both menstrual pain and headaches, regardless of the underlying causes, are often relieved by OTC NSAIDs and analgesics. The pain more prevalently experienced by the 50 -year olds, ie joint pain and pain in legs or knees, is more likely relieved by prescribed analgesics.

NSAIDs and analgesics constitute a group of medicines that are used extensively throughout the world. Since much of the consumption stems from nonprescription purchases, there is less insight about the use of these medicines compared with those sold by prescription only. Prescription-free medicines are often perceived by consumers as less risky than other medicines, ${ }^{27}$ while they in fact may have serious consequences, even in therapeutic doses, for individuals with certain conditions. ${ }^{28-30}$ Good methods to study the use of these medicines are therefore needed. The high extent of intra-individual variability in reported medicine 
use shown by the two modes in the current study underlines the need for careful consideration of questionnaire design and the wording of specific questions. This may be particularly relevant in large studies employing various questionnaires and clinical examinations, where medicine use may not receive sufficient attention in study design.

If an interviewer-administered approach is chosen, it is also important to provide clear interview instructions so that the data collection is conducted as uniformly as possible, especially if several interviewers are involved. As shown by the current study, we need to consider whether the same questions have been asked, when we combine or compare results from different data collections.

Several of the weaknesses discussed regarding different ways of collecting data on medicine use also affect the validity of the current methodological study. Clearly, the questions were differently phrased, for instance in terms of time frame. In the self-administered questionnaire, the participants were asked to report "use" (ie any use daily, weekly or monthly), whereas the interviewer just asked "what are you using", allowing the participants to interpret the meaning of "use" themselves. Another difference was that the participants were asked by the interviewer to report OTC use together with prescription medicine use.

In future population-based studies, researchers should keep in mind that different modes of data collection yield different results on self-reported medicine use. Ideally, we should collect data using complementary methods. If this is not possible, due to for instance resource restraints, practical challenges or ethical considerations, the results of this study suggest that a self-administered questionnaire that can be filled in at home where the participants have their medicines available would result in a higher prevalence of self-reported use of NSAIDs and analgesic medicines compared with an interviewer-administered questionnaire conducted at the study site. Items in selfadministered questionnaires should be self-explanatory, preferably closed-ended, and supplemented with examples.

\section{Conclusion}

This study among middle-aged Swedish women showed that different modes of data collection yielded large variations in self-reported use of NSAIDs and analgesic medicines. The use of a self-administered questionnaire with closed-ended medicine-specific questions identified more users of NSAID and analgesic medicines compared with an interviewer-administered questionnaire with open-ended questions. Reported use according to the self-administered questionnaire was also more strongly associated with experienced pain.

\section{Data Sharing Statement}

The datasets used and/or analyzed during the current study are available from the corresponding author on reasonable request.

\section{Acknowledgments}

We would like to thank Ann-Christine Lindahl (The University of Gothenburg) for clarification regarding the conduct of the data collection. The Population Study of Women in Gothenburg was financed by grants from the Swedish Research Council for Health, Working Life and Welfare (FORTE 2007-1958), the Swedish State under the agreement between the Swedish Government and the county council (the ALF agreement GBG-68771) and The Health \& Medical Care Committee of the Region Västra Götaland.

\section{Disclosure}

The authors declare that they have no competing interests.

\section{References}

1. Moore N, Pierfitte C, Pehourcq F, Lagnaoui R, Bégaud B. Comparison of patient questionnaires, medical records, and plasma assays in assessing exposure to benzodiazepines in elderly subjects. Clin Pharmacol Ther. 2001;69(6):445-450. doi:10.1067/mcp.2001.116147

2. Dorne JL. Impact of inter-individual differences in drug metabolism and pharmacokinetics on safety evaluation. Fundam Clin Pharmacol. 2004;18(6):609-620. doi:10.1111/j.1472-8206.2004.00292.x

3. Murali KM, Mullan J, Chen JH, Roodenrys S, Lonergan M. Medication adherence in randomized controlled trials evaluating cardiovascular or mortality outcomes in dialysis patients: a systematic review. BMC Nephrol. 2017;18(1):42. doi:10.1186/ s12882-017-0449-1

4. Stirratt MJ, Dunbar-Jacob J, Crane HM, et al. Self-report measures of medication adherence behavior: recommendations on optimal use. Transl Behav Med. 2015;5(4):470-482. doi:10.1007/s13142-0150315-2

5. Wettermark B, Hammar N, Fored CM, et al. The new Swedish prescribed drug register--opportunities for pharmacoepidemiological research and experience from the first six months. Pharmacoepidemiol Drug Saf. 2007;16(7):726-735. doi:10.1002/ pds. 1294

6. Wetzels G, Nelemans P, Schouten J, van Wijk B, Prins M. All that glisters is not gold: a comparison of electronic monitoring versus filled prescriptions--an observational study. BMC Health Serv Res. 2006;6 (1):8. doi:10.1186/1472-6963-6-8

7. Gama H, Correia S, Lunet N. Questionnaire design and the recall of pharmacological treatments: a systematic review. Pharmacoepidemiol Drug Saf. 2009;18(3):175-187. doi:10.1002/pds.1703 
8. West SL. A comparison of data sources for drug exposure ascertainment in pharmacoepidemiologic studies with emphasis on self-reported information. Pharmacoepidemiol Drug Saf. 1997;6 (3):215-218. doi:10.1002/(SICI)1099-1557(199705)6:3<215::AIDPDS289>3.0.CO;2-Y

9. Bertoldi AD, Barros AJ, Wagner A, Ross-Degnan D, Hallal PC. A descriptive review of the methodologies used in household surveys on medicine utilization. BMC Health Serv Res. 2008;8(1):222. doi:10.1186/1472-6963-8-222

10. Lewis JD, Strom BL, Kimmel SE, et al. Predictors of recall of over-the-counter and prescription non-steroidal anti-inflammatory drug exposure. Pharmacoepidemiol Drug Saf. 2006;15(1):39-45. doi:10.1002/pds.1134

11. West SL, Savitz DA, Koch G, Strom BL, Guess HA, Hartzema A. Recall accuracy for prescription medications: self-report compared with database information. Am J Epidemiol. 1995;142 (10):1103-1112. doi:10.1093/oxfordjournals.aje.a117563

12. Sundermann AC, Hartmann KE, Jones SH, Torstenson ES, Velez Edwards DR. Validation of maternal recall of early pregnancy medication exposure using prospective diary data. Ann Epidemiol. 2017;27(2):135-139.e132. doi:10.1016/j.annepidem.2016.11.015

13. Klungel $\mathrm{OH}$, de Boer A, Paes AH, Herings RM, Seidell JC, Bakker A. Influence of question structure on the recall of self-reported drug use. J Clin Epidemiol. 2000;53(3):273-277. doi:10.1016/S0895-4356(99)00167-5

14. Neutel CI, Walop W. Comparing two different approaches to measuring drug use within the same survey. Chronic Dis Can. 2000;21 (4):150-156.

15. van den Brandt PA, Petri H, Dorant E, Goldbohm RA, van de Crommert S. Comparison of questionnaire information and pharmacy data on drug use. Pharm Weekbl Sci. 1991;13(2):91-96. doi:10.1007/ BF01974987

16. Bowling A. Mode of questionnaire administration can have serious effects on data quality. J Public Health (Oxf). 2005;27(3):281-291.

17. Lunet N, Bastos J, Cumaio F, Silva P, Dias E, Barros H. Recall of drug utilization depends on subtle structural questionnaire characteristics. Pharm World Sci. 2008;30(2):175-181. doi:10.1007/ s11096-007-9161-8

18. Ademi Z, Turunen JH, Kauhanen J, Enlund H. A comparison of three questionnaire-based measures of analgesic use over 11 years in adult males: a retrospective analysis of data from a prospective, population-based cohort study. Clin Ther. 2007;29(3):529-534. doi:10.1016/S0149-2918(07)80090-7

19. Bengtsson C, Blohmé G, Hallberg L, et al. The study of women in Gothenburg 1968-1969-a population study. General design, purpose and sampling results. Acta Med Scand. 1973;19(4):311-318.
20. Prospective Population Study of Women in Göteborg (PPSW). Swedish national data service. Available from: https://snd.gu.se/en/ catalogue/study/snd0009. Accessed March 30, 2021.

21. The RAND Corporation. 36-Item short form survey (SF-36) scoring instructions. Available from: https:/www.rand.org/health-care/sur veys_tools/mos/36-item-short-form/scoring.html. Accessed March 30,2021 .

22. Håkonsen $\mathrm{H}$, Andersson Sundell K, Martinsson J, Hedenrud T. Consumer preferences for over-the-counter drug retailers in the reregulated Swedish pharmacy market. Health Policy. 2016;120 (3):327-333. doi:10.1016/j.healthpol.2016.01.016

23. Hedenrud T, Håkonsen H. Purchase habits, use of paracetamol, and information sources on a reregulated Swedish pharmacy market: a population-based study. Health Policy. 2017;121(1):35-41. doi:10.1016/j.healthpol.2016.11.009

24. Håkonsen $H$, Wängberg M, Alani D, Hedenrud T. Generic versus brand-name over-the-counter analgesics: knowledge and attitudes among Swedish pharmacy customers. $J$ Pharm Policy Pract. 2020;13(1):60. doi:10.1186/s40545-020-00269-5

25. Krantz E, Wide U, Trimpou P, Bryman I, Landin-Wilhelmsen K. Comparison between different instruments for measuring health-related quality of life in a population sample, the WHO MONICA project, Gothenburg, Sweden: an Observational, Cross-Sectional Study. BMJ Open. 2019;9(4):e024454. doi:10.1136/ bmjopen-2018-024454

26. Jönsson S, Hange D. Secular trends in self-assessed health over 24 years among 38-, 50-, 70- and 75-year-old women: observations from the prospective population study of women in Gothenburg. Int J Gen Med. 2020;13:261-270. doi:10.2147/IJGM.S243590

27. Droege M, Maniscalco M, Daniel KL, Baldwin HJ. Consumers' risk perceptions of prescription and over-the-counter medications. J Pharm Tech. 2007;23(3):142-147. doi:10.1177/ 875512250702300303

28. Harirforoosh S, Asghar W, Jamali F. Adverse effects of nonsteroidal antiinflammatory drugs: an update of gastrointestinal, cardiovascular and renal complications. J Pharm Pharm Sci. 2013;16(5):821-847. doi:10.18433/J3VW2F

29. Tittarelli R, Pellegrini M, Scarpellini MG, et al. Hepatotoxicity of paracetamol and related fatalities. Eur Rev Med Pharmacol Sci. 2017;21(1 Suppl):95-101.

30. Roberts E, Delgado Nunes V, Buckner S, et al. Paracetamol: not as safe as we thought? A systematic literature review of observational studies. Ann Rheum Dis. 2016;75(3):552-559. doi:10.1136/ annrheumdis-2014-206914
International Journal of General Medicine

\section{Publish your work in this journal}

The International Journal of General Medicine is an international, peer-reviewed open-access journal that focuses on general and internal medicine, pathogenesis, epidemiology, diagnosis, monitoring and treatment protocols. The journal is characterized by the rapid reporting of reviews, original research and clinical studies across all disease areas. The manuscript management system is completely online and includes a very quick and fair peer-review system, which is all easy to use. Visit http://www.dovepress.com/ testimonials.php to read real quotes from published authors. 